\title{
DE LA COTIDIANIDAD A LA RITUALIDAD DE LAS CALABAZAS DURANTE EL PERÍODO INTERMEDIO TARDÍO EN EL DESIERTO DE ATACAMA, CHILE
}

\author{
FROM EVERYDAY LIFE TO THE RITUALITY OF THE GOURD VESSEL DURING \\ THE LATE INTERMEDIATE PERIOD IN THE ATACAMA DESERT, CHILE
}

\author{
Cristí́n Olinares Acuña ${ }^{A}$
}

\begin{abstract}
Se analizan las representaciones visuales de calabazas pirograbadas del norte de Chile atribuidas al Período Intermedio Tardío (1000-1430 DC) a partir de un enfoque arqueosemiótico materialista, relacionando la semiótica de Peirce con categorías de la sociedad concreta. Se identifica una división entre sus usos y formas de sociabilidad en la vida cotidiana-doméstica y ritual mágico-religiosa, y se conciben como soportes iconográficos que reflejan las formas de conciencia social de un grupo dominante. Se concluye que estos objetos fúnebres y sus signos no solo representan bienes de prestigio y distinción, sino también ejercen una función ideológica en las relaciones de poder, vinculadas con el consumo de bebidas fermentadas, sustancias enteogénicas y estados alterados de conciencia.

Palabras clave: materialismo histórico, arqueosemiótica, calabazas pirograbadas, iconografía, ideologías.
\end{abstract}

This paper analyzes the visual representations of pyrographed gourds from the north of Chile attributed to the Late Intermediate Period (1000-1430 AD). The analysis is carried out from a materialistic archaeosemiotic approach, relating Peircean semiotics to categories of the concrete society. A division is identified between the uses of the gourds and forms of sociability in daily-domestic and magical-religious ritual life, and the gourds are conceived as iconographic media that reflect the forms of social consciousness of a dominant group. It is concluded that these funeral objects and their signs not only represent prestige and distinction goods, but also manifest an ideological function regarding power relations, linked to the consumption of fermented beverages and entheogenic substances, and to altered states of consciousness.

Keywords: historical materialism, archaeosemiotics, pyrographed gourds, iconography, ideology.

\section{INTRODUCCIÓN}

Eric Louw (1998: 393-396) define la semiótica materialista como un conjunto de abordajes teóricos inspirados en Karl Marx para la producción de signos y comunicación. Esta perspectiva sitúa el contexto socioeconómico en el escenario interpretativo de los signos, pues los códigos y signos no pueden ser estudiados fuera de un tiempo, de un lugar y de las relaciones sociales correspondientes, por cuanto se influencian mutuamente en un contexto histórico-social determinado.

En el presente artículo se propone un enfoque arqueosemiótico materialista, entendido como el estudio de la cultura material por medio de la dialéctica interdisciplinaria entre materialismo histórico y semiótica para la explicación de los signos en la realidad concreta, tanto en sus aspectos materiales como ideológicos. Considerando las calabazas pirograbadas y sus características de índole visual, esta investigación sustenta su análisis en la semiótica de Peirce, con referencia al objeto, y en el materialismo histórico que ha inspirado la Arqueología Social Latinoamericana (ASL).

En términos específicos, se realiza un estudio de tres calabazas pirograbadas encontradas en el desierto de Atacama, atribuidas al Período Intermedio Tardío (1000-1430 DC). La elección de este período específico se

\footnotetext{
A Cristián Olivares Acuña, Universidade Federal de Sergipe, Sergipe, Brasil. ORCID: 0000-0003-4578-3056.

E-mail: cristian.olivares1989@gmail.com
} 


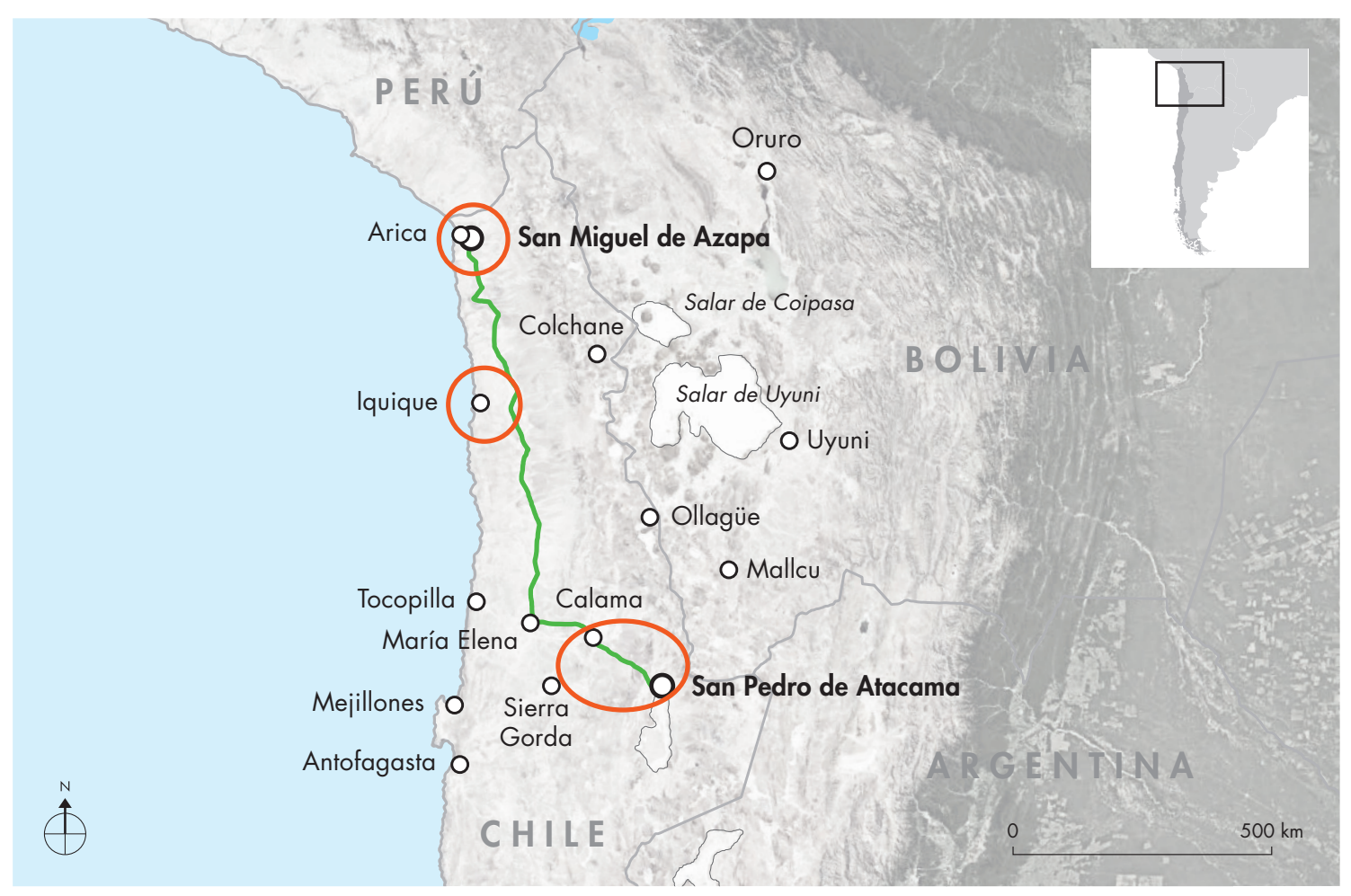

Figura 1. Mapa del desierto de Atacama. Los círculos en rojo corresponden a las áreas donde fueron encontradas las calabazas de las colecciones museológicas. Figure 1. Map of the Atacama Desert. Red circles indicate areas where the gourds of the museum collections were found.

debe a la abundancia de calabazas (Lagenaria siceraria) como ofrendas funerarias, sustituyendo la presencia de cerámicas y muchas veces siendo el único objeto fúnebre (Castro et al. 2016). Actualmente se almacenan en el Museo Chileno de Arte Precolombino (MCHAP) y en la Corporación de Cultura y Turismo de Calama (ССтC) y, según las fichas museológicas consultadas, los recipientes se concentran en tres áreas geográficas del norte de Chile (fig. 1): Provincia de Arica, Provincia de Iquique y Provincia de El Loa (que abarca los sectores de Calama y San Pedro de Atacama).

Hasta el momento, los pocos estudios que existen sobre este tipo de contenedores se centraron en la descripción de motivos (antropomorfos, zoomorfos y geométricos) y técnicas decorativas (incisiones, pirograbado, inciso-punteado). Estas clasificaciones contribuyeron al establecimiento de secuencias histórico-culturales y espaciales; sin embargo, raramente trascendieron la esfera de la migración y difusión de ideas en la interpretación arqueológica (Ambrosetti 1907; Oyarzún 1929; Latcham 1938; Plath 1957; Durán 1976; Alfaro \& Gentile
1978; Costa \& Llagostera 1984). El mayor problema de lo anterior reside en que limitaron el análisis referente al papel de las calabazas solo a recipientes domésticos, sin preguntarse sobre otras formas de sociabilidad e interacción en las comunidades andinas precolombinas.

Por tales motivos, se busca profundizar en los vínculos interpretativos de ícono, índice y símbolo con las categorías de la sociedad concreta (formación económico-social, modo de vida y cultura), que consideran desde las regularidades de mayor nivel de acción causal y estructural, hasta el nivel de existencia fenomenal y singular de la sociedad (Bate 1998), para entender las continuidades, mudanzas y diferencias entre las comunidades del desierto. También, el explorar la hipótesis del chamanismo y los estados alterados de conciencia vinculados a las calabazas pirograbadas desde el enfoque arqueosemiótico materialista, se muestra como un camino interesante para explicar las relaciones sociales de producción, género, ideología, paisaje y los cambios históricos. 


\section{CONTEXTO HISTÓRICO Y MARCO SOCIAL}

Muchos autores coinciden en que, una vez desaparecida la influencia de Tiwanaku, se inició una nueva etapa cultural denominada Período Intermedio Tardío o de Desarrollos Regionales (1000-1430 DC), caracterizada por las disputas políticas y territoriales entre las comunidades de San Pedro, reinos aymaras provenientes del Altiplano y autoridades del Noroeste Argentino (Le Paige et al. 1978; Castro 2001; Fuentes \& Soto 2009). Posteriormente, se impuso un aparente momento de paz, estabilidad política y alianzas interétnicas que favorecieron el tráfico caravanero y comercial.

En este contexto, las comunidades del desierto se reorganizaron en una sociedad de clases, con identidades locales definidas a partir de la materialidad y los atributos iconográficos. En términos mortuorios, en aquella época, la mayoría de los grupos habitantes de esa área compartían determinados elementos en sus ajuares funerarios, tales como cestería, semillas de algarrobo y chañar, calabazas decoradas, instrumentos para uso de alucinógenos, entre otros. De acuerdo con Castro y colaboradores (2016: 273, citando a Schiappacasse et al. 1989), "en este período son las calabazas y el arte rupestre los soportes que contienen la mayor parte de la iconografía".

A pesar de la abundancia de los frutos de Lagenaria siceraria en las ofrendas mortuorias durante el período estudiado, los enfoques tradicionales y los estudios cerámicos, textiles, arte rupestre y parafernalia alucinógena, dejaron de lado las discusiones y el potencial interpretativo de las calabazas y sus atributos en las reservas técnicas de los museos. Sin embargo, el interés por las funcionalidades y los usos de las calabazas está presente en casi todos los lugares del mundo, inclusive puede haber inspirado el surgimiento de vasos cerámicos (Rice 1987: 8, citando a Joesink-Mandeville 1973).

\section{ASPECTOS CONCEPTUALES: HACIA UNA ARQUEOSEMIÓTICA MATERIALISTA}

Como fue dicho, la base de este artículo se identifica con la Arqueología Social Latinoamericana (ASL) que, inspirada por el materialismo histórico dialéctico de Karl Marx y sus sucesores, presenta un conjunto de teorías prácticas y críticas comprometidas socialmente, porque se considera que "la arqueología no empieza ni termina con el objeto; empieza con seres humanos y termina con ellos. Es una ciencia que se basa en la comunicación, el estudio y la defensa de la propia vida" (Tantaleán \& Aguilar 2013: 25).

Enfatizando la dimensión estructural e histórica en los procesos sociales, Bate (1998: 56-68) conceptualiza la sociedad como una totalidad concreta a partir de la triple relación entre:

a) Formación social, entendida como las relaciones generales y fundamentales entre la estructura y la causalidad social, comprendiendo la base material del ser social (que abarca los modos de producción y reproducción con sus subcategorías) y las superestructuras (compuestas por la psicología social y la institucionalidad con sus unidades) que integran la unidad real de la sociedad. En esas categorías, las contradicciones fundamentales de los modos de producción condicionarían el tipo de superestructura, caracterizando la especificidad de las formaciones económicas y sociales.

b) Modo de vida, que expresa las particularidades de la formación socioeconómica, actuando como eslabón intermediario entre el carácter esencial de la formación social y sus manifestaciones en la cultura (Bate 1998: 65). Entre los factores que inciden en esta categoría destacan las especificidades de la organización técnica y social determinada por las condiciones y circunstancias en que viven los seres, o sea, el medio y su transformación por medio del trabajo, y las especificidades de organización y dinámica social que responden a los contactos entre diversos grupos sociales. Teniendo en cuenta la dimensión temporal, el modo de vida también implica distinguir el ritmo histórico de los modos de producción y las diferentes formaciones sociales determinadas por estos.

c) Cultura, como una síntesis de la relación tricategorial, puesto que se refiere a "un conjunto singular de formas fenoménicas que presenta toda sociedad real, como efecto multideterminado por las condiciones concretas de la existencia de una formación social" (Bate 1998: 68. Cursivas en el original).

Esa nueva consideración sobre el modo de vida producto de la interacción entre las diversas categorías de la sociedad representaría una dialéctica entre el ser social (entendido como la totalidad de las relaciones materiales 
y objetivas entre las personas) y las superestructuras (que son los sistemas de ideas y reflejos condicionados por la práctica del ser social y las instituciones). Por un lado, cabe destacar que estas categorías son dinámicas, puesto que cobran sentido y se expresan en la realidad, principalmente en la propia actividad social, estableciendo la ocupación que objetos y personas asumen en determinados momentos y lugares como objetos de trabajo, fuerza de trabajo, medios de producción y como productos. Por otro, estas categorías no implican fijar categóricamente significados, ni designar significados consiste en otorgar un contenido positivo y estático, puesto que una categoría puede atravesar las otras, debido al hecho de que estas son siempre históricas (Lull 2005: 11-12).

El papel de la semiótica y su relación con la arqueología no es un tema nuevo, como bien constata Robert Preucel en su libro Archaeological Semiotics (2006: 2), quien considera la arqueología como una actividad esencialmente semiótica, debido a que busca entender las relaciones entre teoría, datos y prácticas sociales para interpretar la cultura material. En este escenario, la semiótica peirceana se presenta como un enfoque mediador interesante para el análisis de los signos diseñados en las calabazas, puesto que el modelo triádico de Charles Peirce "concibió la semiótica como una forma de vida irreducible, englobando seres humanos y la naturaleza" (Preucel 2006: 45).

Para Peirce (1974: 30-31), las categorías universales de ícono, índice y símbolo se refieren básicamente a la subdivisión del signo con referencia al objeto:

a) ́́cono representa al objeto que se designa meramente en virtud de sus caracteres propios, independiente de la existencia del objeto. Es un ícono de alguna cosa, en la medida en que presenta características en común con el objeto representado a partir de sus semejanzas.

b) Índice como un signo que se refiere al objeto que denota en virtud de ser realmente afectado por aquel objeto. Esta relación causal entre índice y el objeto designado, es de carácter indicativo más que representativo, y se caracteriza por el dominio de la experiencia y de la realidad empírica.

c) Símbolo habla sobre el objeto que denota en virtud de una ley, entendido usualmente como una asociación de ideas generales que operan de modo tal que son la causa de que el símbolo se interprete como referido a un objeto determinado. Debido a su carácter de ley o tipo general, actúa mediante una réplica.
En la identificación de los distintos tipos de signos que los seres humanos utilizan en la mediación semiótica de la cultura, su noción tripartita (ícono, índice y símbolo) es especialmente relevante, y más cuando los significados tienen un papel importante en la negociación de las relaciones de poder, y pueden ser vistos como ideologías semióticas (Preucel 2006: 4). En este sentido, la materialización social de las cosas se define dentro del contexto de la ideología, los intereses sectarios y las luchas por el poder, "que se reflejan en la producción, el control y la manipulación de símbolos, íconos, objetos y monumentos arquitectónicos" (Martel \& Giraudo 2014: 23).

Desde otra perspectiva, Eco (1994) explica cómo las fuerzas materiales que actúan sobre las superestructuras son el universo de la semiosis (entendida como una acción o influencia ilimitada entre tres entidades semióticas, que nunca acaba en una acción binaria). Efectivamente, en la medida en que las fuerzas se expresan en signos, para ser comprendidas y pensadas en las relaciones económicas, de valor y en comunicaciones ideológicas que se insertan en la semiosis, son influenciadas por este proceso que "establece las premisas para las actitudes prácticas que rigen el cambio de estas mismas fuerzas" (Eco 1994: 189).

Por lo tanto, esas premisas semióticas poco a poco establecen puentes analíticos entre el materialismo histórico y la semiótica, principalmente porque el signo siempre estará presente en la disputa por el poder en el interior de un marco ideológico que sustenta las prácticas sociales. En palabras de Valentin N. Volóchinov (1976 [1930]: 36), atribuidas a veces al propio Mikhail Bakhtin, "el signo se convierte en la arena de la lucha de clases". De tal modo, signos que pueden ser rotulados frecuentemente de simbólicos, rituales y ceremoniales, en realidad pueden ocultar algún sentido de dominación o resistencia ideológica y social.

\section{ESTADO DE LA CUESTIÓN: LA PRESENCIA DE CALABAZAS PIROGRABADAS EN LOS ESTUDIOS ANDINOS}

Los primeros registros de calabazas en el área circumpuneña corresponden al estudio de Juan Ambrosetti (1899: 117) en la región Calchaquí. Durante sus exploraciones en Hualfín, encontró una tumba con seis cuerpos acompañados, entre otras cosas, por un mate (hecho de Lagenaria siceraria) grabado a fuego, representando 


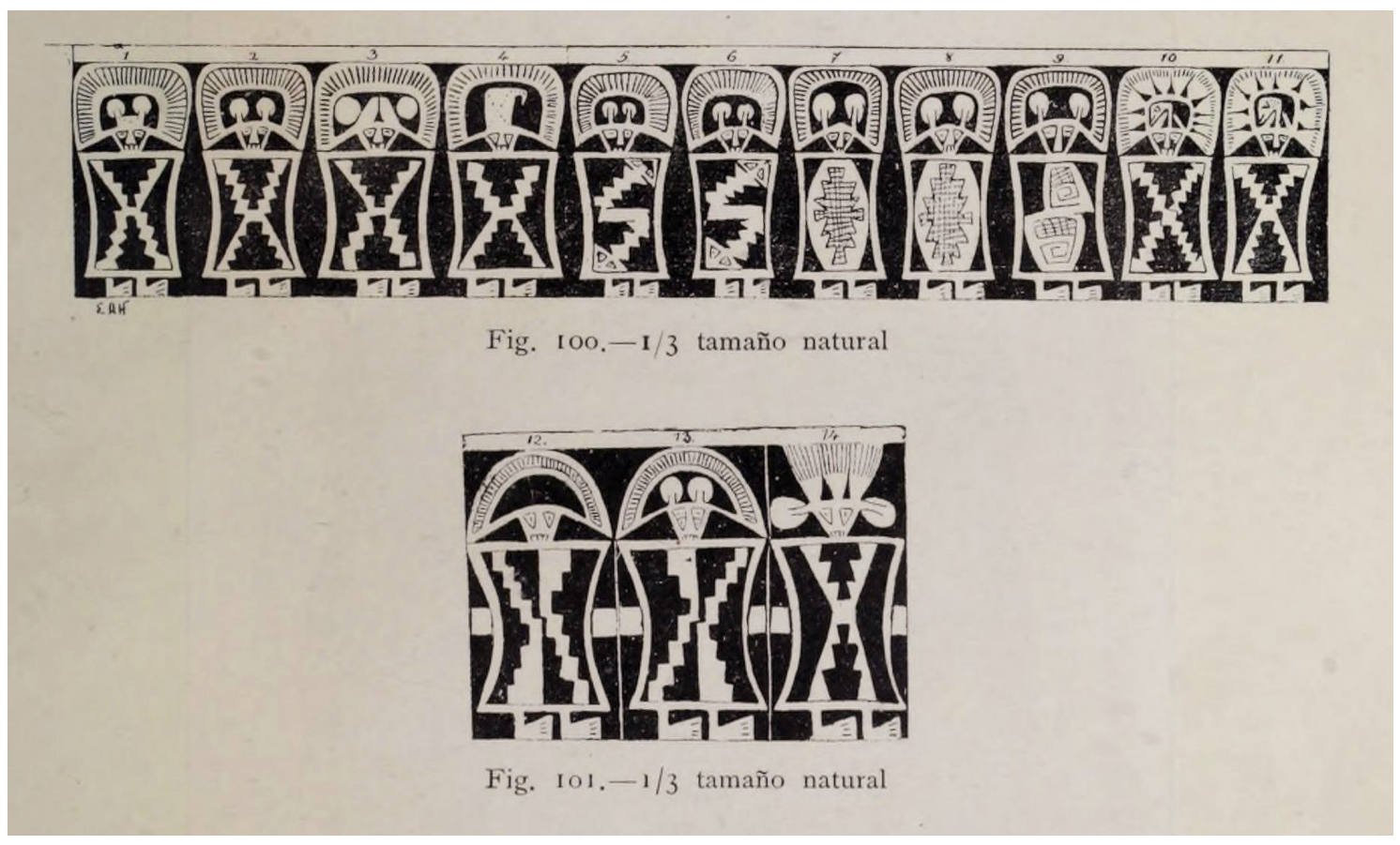

Figura 2. Representación de personajes pirograbados con adornos de plumas y vestimentas (en Ambrosetti 1899: 119, figuras 100 y 101). Figure 2. Rendering of pyrographed characters with feather ornaments and clothing (in Ambrosetti 1899: 119, figures 100 and 101).

11 personajes con diferentes adornos y vestimentas. El naturalista y arqueólogo argentino, más allá de centrar su atención en la técnica del pirograbado, se interesó por los penachos indígenas representados en la calabaza, interpretándolos como emblemas de poder masculino. Igual preocupación mostró por las vestimentas de los personajes, que, según él, podrían representar formas de escudos utilizados por guerreros (hipótesis que fue repetida por otros autores, como se verá más adelante). En cuanto a sus diseños, estos podrían ser "tótems de tribus" o "distintivos personales de cada jefe" (fig. 2).

En la ciudad prehistórica de La Paya (valle Calchaquí, Provincia de Salta), Ambrosetti (1907: 522) se encontró nuevamente con la frecuente presencia de mates hechos de calabazas en las sepulturas y los vinculó a un uso doméstico por mujeres, como "recipientes para guardar semillas y otras menudencias". Posteriormente, destaca su interés por los adornos simbólicos de los objetos hechos por el contacto con el fuego, identificándolos como diseños simples y complejos, confiando en que no "deben haber sido de uso común" (1907: 525).

En otro estudio relacionado con la temática, el antropólogo Eric Boman (1908: 375) recuperó en el Noroeste Argentino muchas calabazas partidas en el medio, transformadas en cuencos o vasijas, con decoraciones geométricas complejas pirograbadas por medio de "puntos incandescentes utilizados para el grabado". Refiriéndose a los colores utilizados por los habitantes de Tastil, el autor también describe que la mayoría de los recipientes de cerámica, incluidas las calabazas, eran pintadas con ocre rojo (color asociado generalmente a mujeres, menstruación y fecundidad) y que, en una oportunidad, encontró polvo de carbonato de cobre en una pequeña calabaza (Boman 1908: 375).

Boman (1908: 747) también identificó la presencia de vainas de algarrobo y granos de maíz dentro de las calabazas, incluso indica que "en otro espécimen, todavía vemos el contenido de semillas de Prosopis, formando una masa sólida que se adhiere a la calabaza", lo que puede ampliar las discusiones sobre el papel de las bebidas fermentadas en el norte de Chile. Esta situación fue observada personalmente varias veces al analizar las calabazas con y sin pirograbado almacenadas en el MCHAP y la CCTC, en las cuales todavía es posible percibir esta pasta (probablemente de algarrobo o maíz) en el endocarpio del fruto.

En el Noroeste Argentino y norte de Chile, el rapé de vilca o huilca, comúnmente llamado cebil 
(Anadenanthera colubrina), surge igualmente como otra sustancia que enriquece el debate sobre los estados alterados de conciencia así como el registro arqueológico, puesto que aparece en varios sitios, del mismo modo que las semillas de algarrobo. Ambas semillas poseen descripciones que indican que eran almacenadas en el interior de calabazas (Le Paige 1977: 124; Pérez \& Gordillo 1993: 311-312; Torres \& Repke 2006: 32).

Por su parte, Max Uhle (1913: 109) refiere que las comunidades atacameñas "usaban numerosas calabazas, bien adornadas a fuego, cuyo material se importaba de la Argentina". Este último supuesto ha sido cuestionado por otras investigaciones que serán revisadas posteriormente. En otra oportunidad, Uhle (1922) problematiza sobre la relación entre la civilización Chincha (indígenas de la costa sur del Perú) y comunidades atacameñas, llegando a la conclusión de que entre los grupos hubo una influencia mutua en los elementos decorativos de las calabazas. El uso de volutas, triángulos, rombos, serpientes y otros motivos grabados en las calabazas de Calama, se explicaría "por la extensión y los efectos en regiones lejanas de la civilización chincha-atacameña de la costa del sur del Perú, de Arica y Tacna" (Uhle 1922: 91), muy probablemente debido al tráfico comercial de largas distancias efectuado por caravaneros de llamas.

La mayoría de estas hipótesis fueron apoyadas por Oyarzún (1929: 89), en su texto sobre las calabazas pirograbadas de Calama, al señalar que las calabazas se conocían muchos años antes de la llegada de los españoles al norte de Chile y que "los antiguos habitantes de Atacama se servían de ellas, adornándolas con hermosos grabados, para los usos de la vida ordinaria y como vasos de ofrendas para sus muertos". Indicaba, además, que las comunidades de Atacama ya manejaban el trabajo con metales, al afirmar que adornaban las calabazas "por medio de pirograbado que ejecutaban con punzones finos de cobre" (Oyarzún 1929: 103).

De esta manera, se observa una división en los usos de las calabazas en los modos de vida al interior del desierto, tanto en el aspecto cotidiano-doméstico como en las ofrendas mortuorias. En la práctica, es posible que tal división representara una dialéctica entre las relaciones sociales establecidas junto con su objetivación en las calabazas. Así, desde un punto de vista materialista, es posible que las calabazas sin pirograbado se identificaran más con relaciones económicas de producción y distribución, en tanto que las pirograbadas serían el reflejo de las superestructuras o sistemas de ideas condicionadas por la práctica del ser social en las ceremonias institucionalizadas.

El arqueólogo Ricardo Latcham (1938: 172-173) también presentó varios puntos interesantes en la discusión sobre el análisis de las calabazas. Primero, afirma que el fruto de Lagenaria siceraria fue conocido y cultivado por comunidades atacameñas, por lo que su importación desde Argentina no era necesaria. Segundo, el sistema usado para pirograbar las calabazas no había sido eficientemente estudiado. Para este autor, los diseños eran totalmente pirograbados sin incisiones, y los contornos de cada figura fueron primeramente trazados por una serie de puntos pirograbados que se distanciaban uno a dos milímetros entre sí.

Ese procedimiento era seguido por la unión de los puntos mediante líneas cortas grabadas con la punta ardiente, fuese de metal o de madera, sin la aplicación de cenizas, pinturas u otros colorantes. En otras calabazas los diseños fueron hechos con líneas cortas, distanciadas con unos pocos milímetros entre sí, aunque no siempre unidas. Además, el autor sugiere que, aun siendo la alfarería considerada una actividad esencialmente femenina, el pirograbado fue un recurso masculino (Latcham 1938: 174).

Siguiendo una línea de análisis relacionada con los ritos y la espiritualidad vinculada muchas veces con la medicina, Plath (1957: 159-160) muestra que el fuego y la fermentación de bebidas, como la chicha de algarrobo, generalmente fueron utilizados por "un brujo conocido, mientras pronuncia palabras y hace signos cabalísticos", con el objetivo de sanar o desinfectar el recipiente de gérmenes y bacterias. De acuerdo con Dauelsberg (1974: 28 ), prácticas con fuego también pueden haber servido para fumar ciertas hierbas o para "calentar y cocer alimentos por medio de la inmersión de piedras calientes, ya que presentan en su interior rastros de quemaduras". También aduce que las calabazas se utilizaban para guardar sustancias grasas que tenían relación con las pinturas corporales y faciales, muchas de ellas con una decoración geométrica e interlocking o entrelazada con una distribución panandina (1972: 163-165).

Desde otra perspectiva, María Ester Grebe (1974), al abordar temáticas referentes a la música precolombina, rescata los sonajeros hechos de calabazas que tienen incisiones de pirograbado, sugiriendo connotaciones simbólicas y mágico-religiosas. En este sentido, las calabazas "suelen embellecerse con plumas, ornamento de carácter y significado mágico; o bien con incisiones 

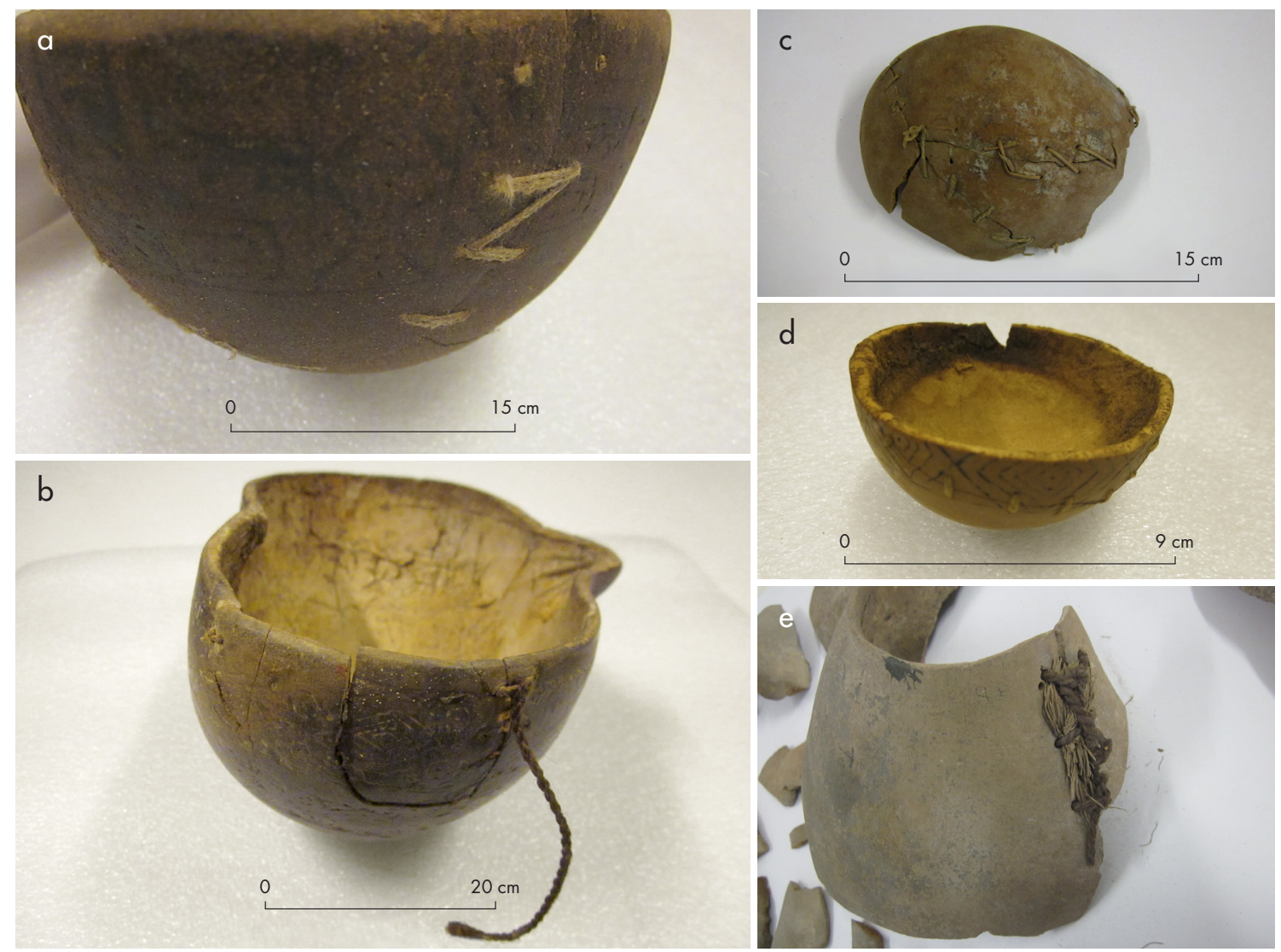

Figura 3. Reparaciones en calabazas pirograbadas y sin pirograbar. Colecciones MCHAP: a) pieza MAs387 reparada verticalmente con cordel encerado; b) pieza MAS 1707 remendada verticalmente con cordel encerado; d) pieza MAs3071 cosida con cordel de origen animal. Colecciones сCтC: c) pieza 1909 reparada con fibras de origen animal; e) pieza J8C7 costurada con cordel encerado y fibras vegetales. Figure 3. Repairs on pyrographed and non-pyrographed gourds. MCHAP collections: a) piece MAs387 repaired vertically with waxed cord; b) piece MAS1707 vertically mended with waxed cord; d) piece MAS3071 sewn up with animal cord. CCTC collections: c) piece 1909 repaired with animal fibers; e) piece J8C7 sewn up with waxed cord and vegetable fibers.

pirograbadas en las paredes... En su interior llevan diversos objetos pequeños con el fin de producir sonido por entrechoque" (1974: 18). Así, transformada en un instrumento musical como el sonajero, la calabaza se vincula con las ceremonias chamánicas y actividades de cura por medio de la exacerbación de los sentidos por su sonido agudo y excitante, puesto que estimula el trance y acompaña la cura con ritmos, danzas y plegarias.

Por su parte, Lidia Alfaro y Margarita Gentile (1978: 9-10), interesadas en realizar un estudio comparativo entre los motivos decorativos de las calabazas del río Doncellas (Argentina) y los frutos pirograbados del norte de Chile, además de observar las diferentes funcionalidades de los frutos de Lagenaria -por ejemplo, vasijas para fermentados, recurso comercial, ofrenda funeraria, instrumento musical y ceremonial-, infirieron que “[...] el mate parece haber estado relacionado sólo a determinados grupos sociales. [...] para uso de la corte y obsequio a los caciques aliados, relegando de esta forma el uso de los mates a los runa o gente del pueblo".

Así, se afirma que las calabazas fueron objetos de diferenciación en las relaciones sociales cotidianas y en los modos de vida tanto en el Noroeste Argentino (NOA) como en las comunidades del desierto de Atacama (Lizárraga 2010). Tal importancia se puede manifestar en sus reparaciones, puesto que "las rajaduras eran cosidas con cordel encerado asegurando el emparche con cera" (Fernández 1980: 11). En este sentido, Costa y Llagostera (1984) explican que las calabazas con y sin decoración fueron remendadas perforando dos orificios en ambos lados de la ruptura, que luego eran unidos por fibras vegetales y de animales (fig. 3). Para estos 
autores, eso significaba que "la calabaza no era fácil de obtener en San Pedro de Atacama, y probablemente la traían de lugares lejanos" (Costa \& Llagostera 1984: 45), rebatiendo así las ideas levantadas por Latcham (1938: 202-203), quien aseguraba el cultivo de las calabazas en el curso superior del río Loa.

Su valoración vinculada al consumo de fermentados y prácticas rituales para la protección, salud y abundancia, también puede ser observada en la asociación frecuente entre las calabazas y los elementos del complejo cebil, como símbolos del poder mágico-ceremonial o estatus social. María Isabel Hernández (1983: 139), basándose en una descripción de los motivos pirograbados, señala la posibilidad de intercambio simbólico por medio de representaciones, junto a la idea de que "algunas unidades morfológicas representadas en las calabazas podrían ser equiparables a fosfenos o imágenes alucinatorias".

Desde otro punto de vista, José Berenguer (1985, 1995, 1999, 2009) y Axel Nielsen $(1997,2007)$ ven las calabazas como expresión de arte mueble vinculado estrechamente con el arte rupestre de los caravaneros y el ceremonialismo llamero, afirmando que estas son típicas del Período Intermedio Tardío en el área circumpuneña. Ambos autores, siguiendo líneas interpretativas esbozadas por Ambrosetti (1899), sugieren que las figuras antropomorfas con formas de escudo (escutiformes) representarían las tensiones sociales y el potencial bélico de la región, identificado en la construcción de pukaras, cascos, hachas y cuchillos como objetos de poder militar.

Rogger Ravines (1991: 33), analizando los mates ornamentados del Perú, observa que "los elementos de diseños son generalmente geométricos y ocasionalmente figurativos. Sin embargo, en ambos casos repiten patrones textiles". Consecuentemente, los estilos decorativos también se encuentran asociados a los tejidos de la época, tales como inkuñas (paños ceremoniales), chuspas (bolsas de lana para guardar y transportar hojas de coca y artefactos) y túnicas, que, en muchas oportunidades, se encontraron junto con las calabazas.

Para Henning Bischof (1999), la decoración con personajes simbólicos probablemente tenga relación con la mitología, y eso indicaría algún uso ritual de las calabazas que guardaban y fornecían sustancias para actividades mágico-cosmológicas. Una idea relevante de este autor fue la conexión de las vasijas de mate con una mujer identificada como "antecesora de aquellas curanderas conocedoras de plantas medicinales" (Bischof
1999: 95, citando a Donnan 1978: 127). Esta hipótesis resulta relevante debido a que amplía y rompe las anteriores interpretaciones de carácter androcéntrico, que dejaban a las mujeres fuera de los contextos rituales y ceremoniales.

Siguiendo con la reivindicación del rol de las mujeres en los ritos y las ceremonias, como con sus representaciones en las calabazas pirograbadas, Margarita Gentile (2013: 103-104) evidencia que uno de los personajes mostrados en el inicio de este apartado (fig. 2), puede ser efectivamente una imagen de mujer frente a un grupo indígena, principalmente en un contexto fronterizo conflictivo, en el cual las mujeres eran esenciales para el diálogo entre comunidades.

En este contexto de frontera, particularmente durante la expansión inkaica, las calabazas también funcionaron tanto en la mediación de conflictos como en el establecimiento de límites de los territorios prehispánicos, por medio de las capacochas (ceremonias de ofrendas para el Sol), en las cuales las comitivas sacrificaban llamas y luego llenaban de sangre las calabazas para derramarlas en las huacas. En palabras de Gentile (2013: 109), “[...] dos mates con dibujos de la comitiva [...] podrían indicar que en ese punto geográfico se intentó frenar el avance de una frontera, y que esa parte de la comitiva más los mates con las ofrendas se transformaron en el nuevo hito fronterizo $[\ldots]$ ".

Los simbolismos presentes en las calabazas del NOA, principalmente en la figura humana junto con las representaciones del mundo animal (sapos, aves y serpientes), constituirían para Myriam Tarragó (2000: 285-286) un mensaje o narrativa tan cristalizada que "eran usados por parte de grupos sociales como vehículo de expresión y reproducción de contenidos ideológicos y como forma de apropiación de la cosmovisión institucionalizada". De este modo, se reafirma la idea de que las calabazas y sus símbolos eran bienes de prestigio y se relacionaban con el desenvolvimiento de grupos que manejaban un repertorio de signos al interior de la esfera política y sociocultural de las comunidades, cuya significación e interacción también comprendía el norte de Chile, Argentina y sur de Bolivia (Aschero 2000; Castro 2001; Uribe \& Adán 2004; Ávila \& Puente 2008; Troncoso 2011; Podestá et al. 2013).

Aplicando un enfoque experimental, Mulvany y Vasvari (2009) estudiaron diferentes objetos para el pirograbado de la calabaza, tales como espinas de cactus, pedazos de madera, puntas de lascas y punzones 


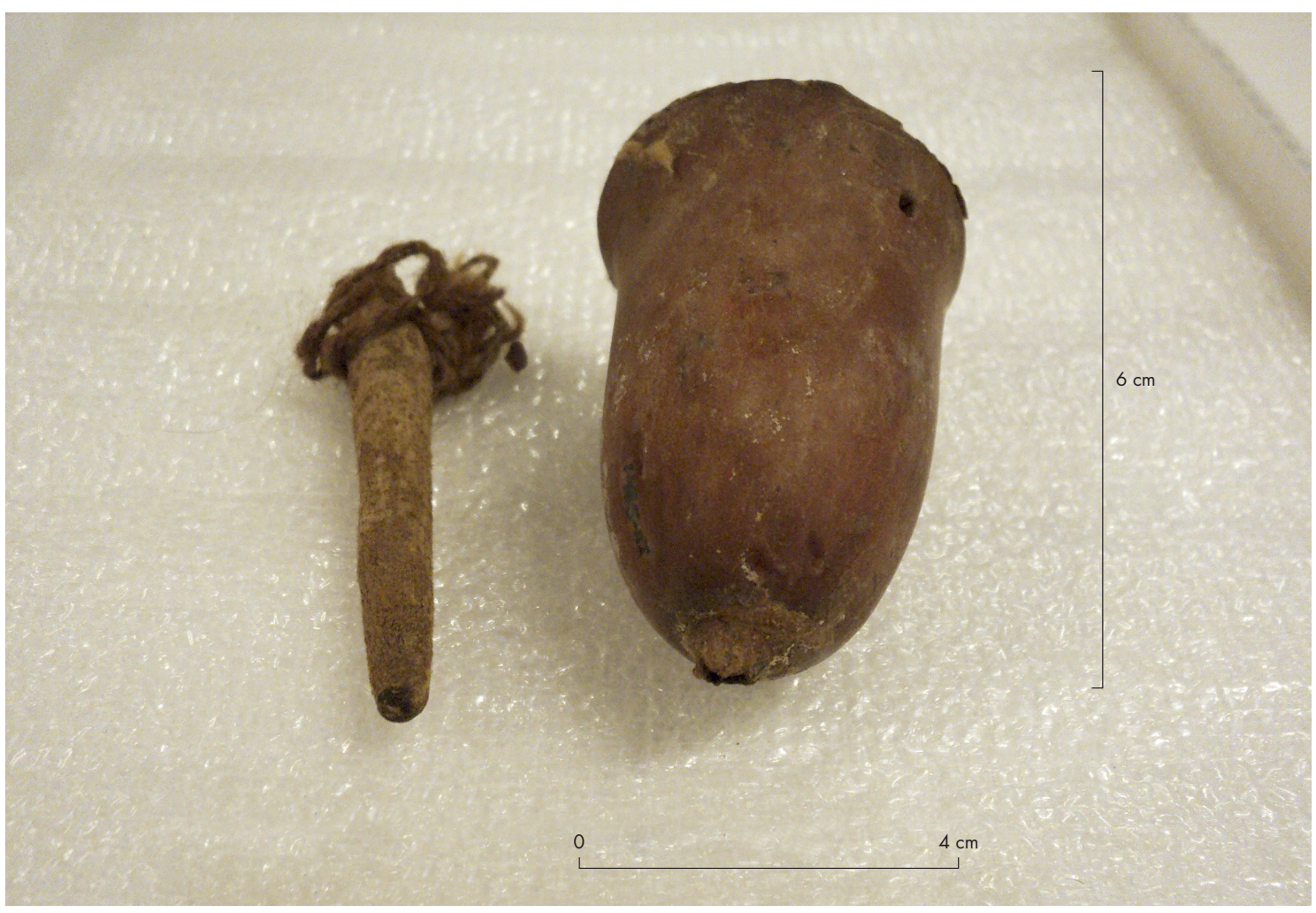

Figura 4. Vara de madera con la punta quemada junto a recipiente de calabaza. Pieza 1485-AI (MCHAP). Figure 4. Wooden rod with burnt tip next to gourd vessel. Piece 1485-AI (MCHAP).

de metal, llegando a la conclusión de que las puntas de origen natural producen un grabado menos certero que aquel elaborado con puntas de metal. Casualmente, entre las colecciones del MCHAP existe un recipiente formado por la parte superior del cuello de la calabaza, en cuyo interior fue identificada una pequeña vara ( $\sin$ registro de especie) con un orificio en su parte superior atravesado por un cordón de lana de camélido y con su punta quemada (fig. 4), que confirma el origen natural para producir grabados.

Pensando que la transformación del recipiente y la incorporación de imágenes, por medio de las técnicas de pirograbado, incisiones y ligación de los puntos quemados, claramente es un proceso creativo que demanda energía, tiempo, habilidades y competencias manuales y de percepción, Mulvany y Vasvari (2009: 402) sugieren que la decoración de calabazas tuvo que ser realizada por personas especialistas con cualidades de precisión en el trazado y buena visión para la producción de detalles de los diseños: "la ejecución de los diseños pirograbados debía realizarse a través de una planificación muy cuidadosa, ya que una vez incidida y quemada la superficie, ésta no podía volver a ser modificada".

Considerando la bibliografía consultada, el último trabajo sobre calabazas pirograbadas en Chile corresponde a la arqueóloga Paola Leiva (2015), quien analizó las calabazas decoradas del extremo norte del país, desde un enfoque estructuralista de los sistemas de representación visual. Para Leiva, estos objetos son concebidos como soportes transmisores de imaginarios e identidades de la cultura Arica, los que mediante las regularidades en las estructuras iconográficas evidenciarían un patrón cognitivo y consensuado socialmente por las poblaciones de los valles occidentales de la región. Entre otras conclusiones, también destacan las ideas sobre la relación entre la estructura iconográfica y la morfología del soporte, principalmente debido a su disponibilidad visual. Sin embargo, su trabajo no consigue alcanzar los objetivos de explorar la funcionalidad social, ritual y utilitaria de las calabazas, como tampoco la correlación con otros objetos o soportes visuales. 

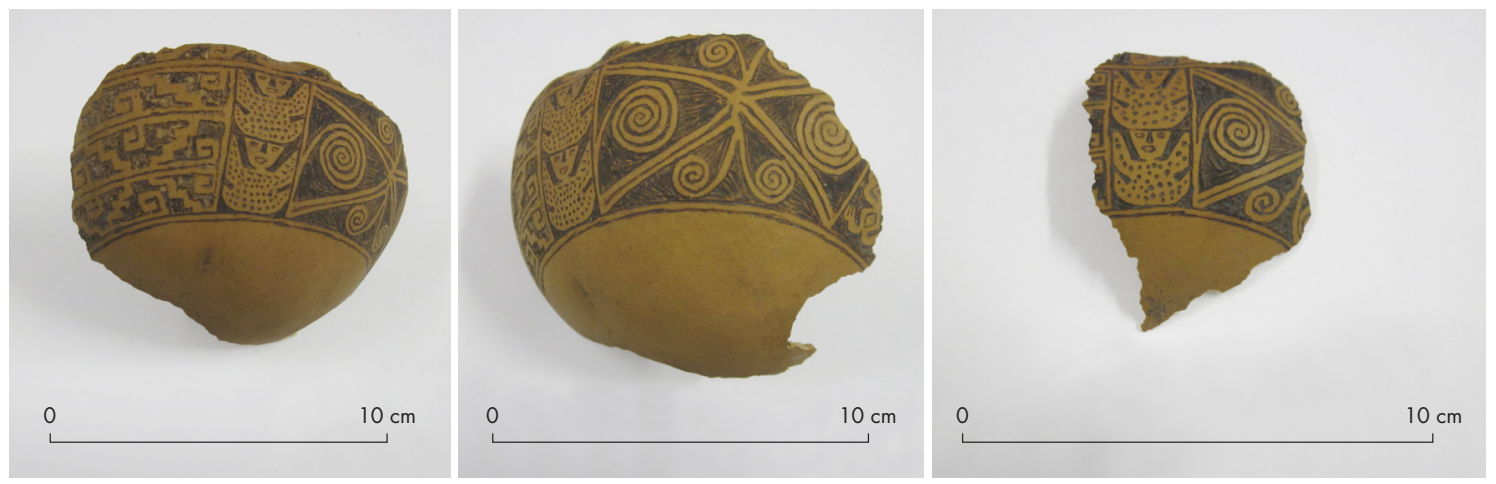

Figura 5. Combinación de representaciones geométricas y figuras antropomorfas con puntos en el cuerpo. CCTC, estante 1E36B, caja 495, pieza 2232, sector Lasana, sin información del contexto. Figure 5. Combination of geometric representations and anthropomorphic figures with dots on their bodies. CCTC, shelf 1E36B, box 495, piece 2232, Lasana area, without context information.

\section{CASOS DE ANÁLISIS POR MEDIO DE LA ARQUEOSEMIÓTICA MATERIALISTA}

En este último apartado se reinterpretan tres ejemplares de calabazas y sus decoraciones por medio de una arqueosemiótica materialista, con el objetivo de entender las diferentes formas de sociabilidad y sus implicaciones como protagonistas en los rituales mágico-religiosos y estados alterados de conciencia.

A continuación, se analizan dos fragmentos de una de las calabazas, ambos pertenecientes al mismo recipiente de forma semiesférica, cortado verticalmente y ornamentado por dos fajas anulares. La primera presenta una secuencia de triángulos con gancho orientados hacia la derecha; la segunda, aparentemente, muestra un juego de tres módulos: a) tres fajas horizontales con un juego de triángulos pirograbados, con escalonado y espirales rectilíneas, separados por líneas anulares; b) dos personajes antropomorfos con puntos en el cuerpo sobre un fondo oscuro; c) un juego de triángulos pirograbados con espirales grandes y pequeños en el interior. Además, en el lado derecho aparece un ser zoomorfo con un rombo con un punto central (fig. 5).

En relación con los aspectos iconográficos, es posible identificar cuatro figuras antropomorfas y una figura zoomorfa. Los íconos de figuras humanas, en términos materialistas vinculados con la categoría de formación social, tienen correspondencia con las relaciones sociales de producción y modos de producción al interior del desierto. En este sentido, como elementos del proceso productivo pueden representar la fuerza de trabajo, "que es la capacidad y energía humana que transforma diversos objetos con el fin de convertirlos en bienes de uso" (Bate 1998: 59). Además, estos íconos también representarían el grado de desarrollo histórico de su sociedad y de las fuerzas productivas, por medio de la organización técnica del trabajo, su división social y la organización social de producción. Así, esta calabaza decorada es una muestra de la rama de producción artesanal y, al mismo tiempo, representa en su pirograbado la existencia de la rama de producción agrícola (como será explicado en los siguientes párrafos).

Los puntos pirograbados en la vestimenta de los antropomorfos representarían índices que posiblemente tienen relación con felinos de pequeño tamaño, como el puma (Felis concolor), el gato andino (Felis jacobita) o el gato de los pajonales o gato montés (Felis colocolo). Esta práctica del ser social tiene relación directa con las categorías que definen las superestructuras y los sistemas de ideas, lo cual nos acerca a la comprensión de la cosmovisión y de los modos de vida de los grupos sociales representados en las calabazas, o sea, a su conciencia social. Por otro lado, sería un índice de prácticas diferenciadas vinculadas con el chamanismo, "con diferentes conjuntos de contenidos de representaciones cognitivas y valores" (Bate 1998: 65). En efecto, generalmente, en la arqueología chilena la imagen del felino representa el alter ego del guerrero-chamán y se relaciona con el consumo de enteógenos como el cebil y cactus San Pedro, puesto que con su ingesta se alcanza la transmutación y simbiosis entre seres humanos y animales tutelares (Nielsen 2007; Berenguer 2009; Horta 2014). De hecho, la nariz marcada en negro también puede ser interpretada como un índice del consumo de enteógenos. 
Siguiendo con el análisis iconográfico, el signo escalonado representaría simbólicamente la serpiente como un rayo de unión entre el cielo y la tierra. Una cuestión importante para los medios de producción y la economía local, debido a que formas serpentiformes y zoomorfas, como el sapo, fueron usadas para convocar lluvias, tempestades y también encarnar los espíritus que cuidan los canales de irrigación en la cultura andina (Grebe 1996). Igualmente, pueden simbolizar la relación entre manifestaciones mágico-rituales e intereses de clases iniciales en la lucha de diferentes formas de creencias. En otras investigaciones, el símbolo escalonado también ha sido interpretado como los escalones de ascensión y descenso, que pueden tener diferentes significados topográficos, orográficos y geográficos, como "planicies, montañas, terrenos ondulados, serranías, cordilleras y andenes" (Posnansky 1913: 7-8). Esta hipótesis es seguida por Horta (2004), quien adiciona la relación entre fuentes de agua y montañas; la pirámide y la representación simbólica de la montaña, donde habitaban las divinidades que controlaban las fuerzas de la naturaleza, las cuales aparecen vinculadas al poder chamanístico y a los fosfenos producto del uso de alucinógenos. Por lo tanto, el triángulo escalonado igualmente representaría una concepción arquitectónica e ideológica del poder, que recuerda los tronos en un templo o espacio sagrado como las huacas, destinadas para ceremonias, rituales, rogativas y sacrificios (Campana 2004).

Explorando la hipótesis acerca de la relación entre las actividades de intercambio, guerra, transmutaciones, ancestralidad y orden político, Berenguer (2009: 199) y Nielsen (2007: 23), apoyados en el texto de Guamán Poma (1980 [1615]), evidencian lo señalado en el párrafo anterior al describir personajes en combate:

Se tornauan en la batalla leones y tigres y sorras y buitres, gavilanes y gatos de monte. $\mathrm{Y}$ ací sus desendientes hasta oy se llaman poma [léon], otorongo [jaguar], atoc [zorro], condor, anca [gavilán], usco [gato montés], y biento, acapana [celajes], páxaro, uayanay [papagayo]; colebra, machacuay, sepiente, amaro (Guamán Poma 1980 [1615]: 52).

En este sentido, en la formación social, los combates fueron institucionalizando ciertas prácticas culto-ceremoniales, en las cuales los animales míticos jugaban un papel importante como ancestros tutelares en los modos de vida y la cultura de las comunidades del desierto. Desde otro punto de vista, esa institucionalidad también representaría la reproducción del sistema social basado en las actividades de coerción y administración de las organizaciones sociales de producción o de afiliación (Bate 1998).

En otra calabaza de forma semiesférica depositada en el MCHAP, se presentan 12 personajes pirograbados, de cuerpo entero observados de frente; cinco utilizan túnicas trapezoidales y tocados de medialuna, y siete son portadores de grandes escudos, penachos y orejeras. Entre ambos grupos se encuentra un tumi o hacha ceremonial (fig. 6). Estas representaciones en formas de escudo fueron descritas e interpretadas inicialmente por Berenguer (1999: 45) como "un motivo que es propio del Noroeste Argentino, donde, seguramente, preceden al arribo de los inkas. Aparecen representados en cerámica y discos de bronce de Santa María y Belén". Por tanto, como íconos simbólicos representarían la reunión de etnias diferentes, organización y dinámica social que daría cuenta de la dimensión histórica de los modos de vida y viabilidad de cambios en el grupo social.

Además de las representaciones icónicas de hachas, armas, cuchillos ceremoniales y otros objetos entendidos simbólicamente como estatus y poder (Aschero 2000; Nielsen 2007; Berenguer 2009), al observar detalladamente los diseños es posible advertir que de los ojos de los personajes caen lágrimas y saliva de la boca, evidenciando indexialmente los efectos del consumo de substancias psicoactivas en algún tipo de ceremonia. Según Ojeda y Ramírez (1993: 18), la intoxicación con cebil (Anadenanthera sp.) provoca, entre otras cosas, que "las mucosas se activan, produciéndose un aflojamiento espontáneo de las fosas nasales, acompañado de salivación, además como consecuencia de la irritación, los ojos producen abundantes lágrimas, también puede haber contracciones de la boca". Consecuentemente, las formaciones de alianzas interétnicas representadas por esos brindis políticos pueden haber sido efectuadas en otro estado de conciencia, tal vez con el objetivo de predecir y saber el futuro de ese contacto étnico, reflexionando sobre dilemas, o bien orientando acciones para resoluciones de conflictos.

Analizando los diseños de una calabaza similar, específicamente aquella encontrada por Ambrosetti (1899) y presentada en la figura 2 del presente artículo, Margarita Gentile (2013: 107) observa que las representaciones antropomorfas (íconos simbólicos debido a la réplica de motivos) están divididas en pares por los mantos que llevan. Estos mantos, entendidos como índices, forman cuatro grupos que "[...] podrían ser los 


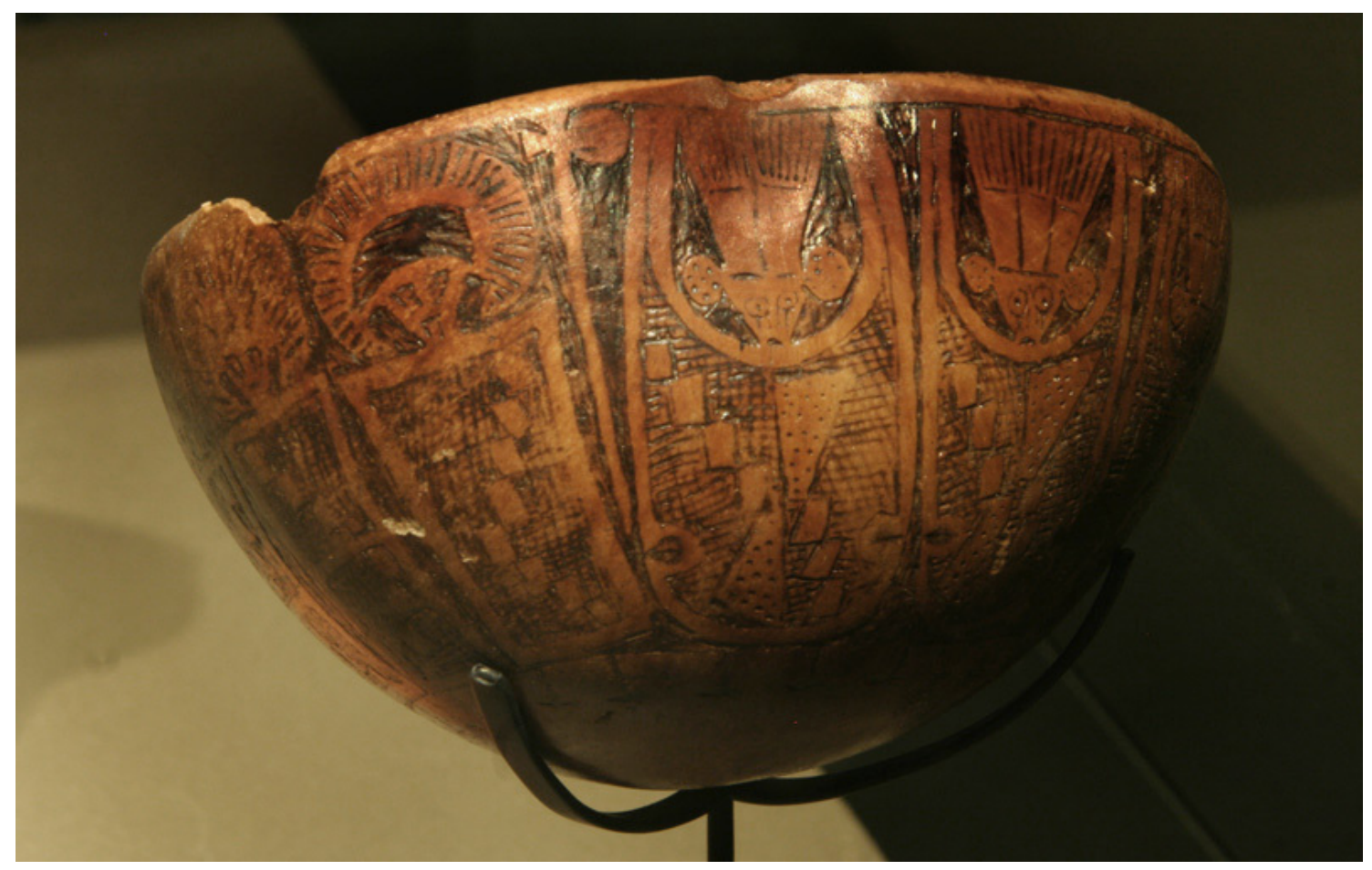

Figura 6. Personajes con túnicas y/o escudos, con efectos de uso de plantas sagradas. MCHAP, pieza MAs3123, Loa (en MCHAP 2012). Figure 6. Characters in robes and/or with shields, with traces of sacred plants use. MCHAP, piece MAS3123, Loa (in MCHAP 2012).

curacas de los aillus que componían una llacta, todos en plan de participar de una capacocha". Asimismo, la autora destaca el papel de las mujeres en el diálogo con otras comunidades para definir las fronteras durante la expansión inkaica, en el cual las calabazas y los rituales que lo acompañaban podrían ejemplificar iconográficamente el acuerdo fronterizo establecido.

En la última calabaza en análisis, se identifican 13 figuras humanas, de cuerpo completo y de frente, una al lado de la otra, diferenciándose nuevamente por los adornos cefálicos y las túnicas que poseen, salvo una figura de cuerpo formado por un rombo concéntrico que aparentemente no posee vestimenta (fig. 7). Nuevamente se observa el destaque de la nariz y los ojos de los personajes, sobre estos últimos se identifica el fenómeno conocido como midriasis, que consiste en el aumento del diámetro de la pupila asociado al consumo de psicoactivos.

Centrando el análisis en la figura con cuerpo de rombo concéntrico, brazos apuntando a la base del recipiente y piernas semiflexionadas, es posible pensar en la representación icónica de una mujer embarazada. Esta figura de connotación femenina y genital, también se vincula con la fertilidad de la tierra y reproducción social en términos materialistas. María Rostworowski y colaboradoras (2003: 136-137) afirman que en la iconografía prehispánica "los genitales femeninos aparecen divinizados al estar asociados a la fecundidad, tanto en el ámbito humano como en el agrícola. Esta relación genital-fecundidad-fertilidad de la tierra se expresaría en el cuerpo de la diosa a manera de metáfora".

Camila Mardones (2012) menciona que la decocción de las hojas de cebil ayuda a la fecundidad de las mujeres, y que dos o tres granos tostados y mixturados con chicha generan una fórmula afrodisíaca. Así, su consumo está relacionado tanto con los modos de reproducción social como con el placer sexual en las prácticas andinas. Se suma también el oficio de parteras, que son poseedoras de conocimientos, técnicas y saberes sobre usos de hierbas en el ciclo de gestación, parto y posparto o puerperio.

De este modo, las calabazas del desierto de Atacama, en especial las del Loa y San Pedro de Atacama, junto 

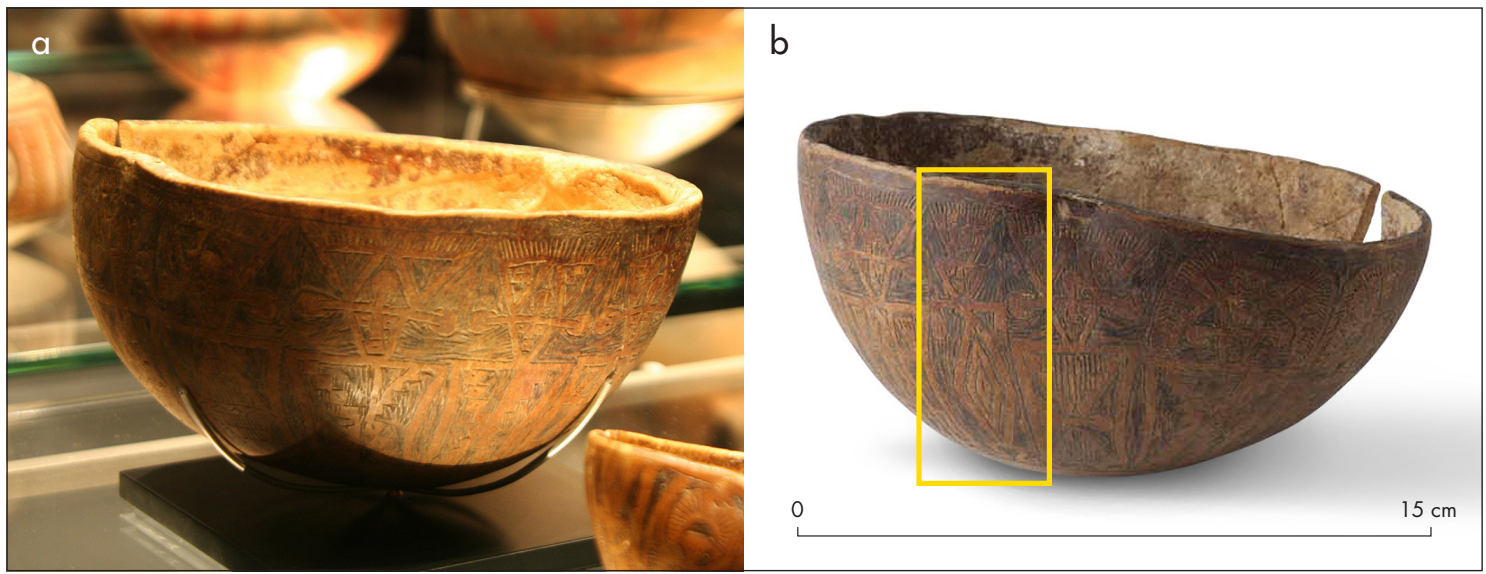

Figura 7. Representaciones de personajes con túnicas, colección MCHAP, pieza MAs2598, sector Loa-San Pedro de Atacama: a) imagen tomada de мснар (2013); b) en recuadro amarillo, detalle de figura femenina (en Gallardo et al. 2011: 80). Figure 7. Representations of characters in robes, MCHAP collection, piece MAS2598, Loa-San Pedro de Atacama area: a) image from MCHAP (2013); b) in the yellow frame, detail of feminine figure (in Gallardo et al. 2011: 80).

con su variabilidad de elementos, motivos y figuras, responden a la creación de unidades particulares de representación vinculadas con la formación social, los modos de vida y la cultura. Se evidencia que las calabazas pirograbadas participan de una dialéctica que solidifica las clasificaciones iconográficas realizadas en el período de estudio y representan las "inferencias de las culturas como sistema de actividades concretas" (Bate 1998: 192). En este sentido, las particularidades de los modos de vida a partir de los signos (ícono, índice y símbolo) mostraron diferentes niveles de sociabilidad, pasando de prácticas económicas a funcionalidades ceremoniales, que daban cuenta de cosmovisiones e ideologías materializadas en sus diseños.

\section{CONSIDERACIONES FINALES}

Finalmente, como fue esbozado en el presente artículo, los frutos de Lagenaria se tornaron reflejo de la percepción del mundo objetivo y del ser social, es decir, de las formas de reconocimiento de la comunidad que se manifiestan mediante signos ideológicos y mágico-rituales. En el juego antagónico de las formas de percepción y conocimiento social se conforma la ideología de las clases dominantes, que no solo necesitan justificar un nuevo tipo de relaciones sociales de producción, sino también imponer una superestructura institucional que acompañe el proceso económico.
En efecto, como se ha expuesto en el breve marco histórico, las identidades locales del desierto de Atacama se fueron definiendo por medio de la materialidad y los atributos iconográficos, destacando entre ellas la presencia de las calabazas pirograbadas que contienen gran parte de iconografía con diferentes signos antropomorfos, zoomorfos y geométricos. Se observa así, en este escenario, cómo los signos continúan o mudan dependiendo de las contradicciones de las fuerzas productivas en un determinado período histórico, volviéndose un factor importante en las luchas de poder entre los grupos sociales, tanto intra- como interétnicos.

A lo largo de este artículo se demostraron las potencialidades interpretativas del enfoque arqueosemiótico materialista en la interpretación de evidencias arqueológicas, especialmente para explorar los signos (íconos, índices y símbolos) presentes en las calabazas pirograbadas en concordancia con el contexto histórico de las comunidades del desierto de Atacama y con las categorías marxistas de formación social, modo de vida y cultura.

En relación con la formación social, se reveló cómo el proceso productivo de las calabazas probablemente estuvo a cargo de artesanos y artesanas especialistas para favorecer el intercambio comercial durante el Período Intermedio Tardío, sobre todo en el caso de las calabazas globulares del norte de Chile, que presentan figuras y patrones iconográficos más estilizados (Leiva 2015). Por otra parte, su presencia como ofrenda en tumbas 
de elite (Horta 2015) representaría contradicciones en las formas de relaciones sociales y modos de vida al interior del desierto. Igualmente, las calabazas pirograbadas de la región del Loa y San Pedro de Atacama simbolizarían atributos de poder y jerarquía social. Aunque también algunas calabazas, por su singularidad, puedan representar la presencia de subculturas definidas por su participación en las actividades y relaciones que se establecen y desenvuelven en la base material del ser social (Bate 1998: 71).

Así, el papel de las calabazas en las comunidades del desierto de Atacama, el control sobre los medios de producción y las relaciones de intercambio, principalmente por parte de la sociedad caravanera de llamas, fueron definiendo el chamanismo del desierto como una singularidad cultural. Además, como fue observado, varios elementos de la superestructura están ligados explícita o implícitamente a los cambios en la infraestructura económica, y los elementos ideológicos que estructuran la sociedad están siempre puestos al servicio de los intereses de esta clase dominante, identificada en el grupo de los caravaneros. Esto se manifiesta en el consumo de ciertos bienes de prestigio y otras materialidades de distinción social. Por lo que, las calabazas, además de funciones medicinales y rituales, representan ideológicamente las relaciones de poder entre opresores y oprimidos, por medio de sus diseños pirograbados y su uso para el consumo de bebidas fermentadas y substancias enteogénicas. Incluso pueden haber cambiado las formas de consumo de plantas sagradas, por ejemplo, reemplazando la de cebil por su mezcla con bebidas fermentadas consumidas en calabazas pirograbadas.

Agradecimientos Expreso mis agradecimientos a Pilar Alliende, Varinia Varela (Museo Chileno de Arte Precolombino, Santiago) y Jannice Rojas Vásquez (Corporación de Cultura y Turismo de Calama) por su ayuda y colaboración. Asimismo, a Francisca Gili y Paola Cristina Leiva, por sus enriquecedores aportes.

\section{REFERENCIAS}

Alfaro, L. \& M. Gentile 1978. Los mates pirograbados de la cuenca del río Doncellas. Antiquitas: 1-11.

Аmbrosetti, J. B. 1899. Notas de arqueología Calchaquí. Buenos Aires: Impr. y Lit. La Buenos Aires.

Ambrosetti, J. B. 1907. Mates. En Exploraciones arqueológicas en la ciudad prehistórica de "La Paya" (Valle Calchaquí,
Provincia de Salta), Campañas de 1906-1907, J. B. Ambrosetti, ed., pp. 522-525. Buenos Aires: Imp. de M. Biedma é hijo.

Aschero, C. 2000. Figuras humanas, camélidos y espacios en la interacción circumpuneña. En Arte en las rocas, M. M. Podestá \& M. de Hoyos, eds., pp. 15-45. Buenos Aires: Sociedad Argentina de Antropología-AAINAPL.

Ávila, F. \& V. Puente 2008. ¿Circulación de símbolos? Calabazas pirograbadas en el Tardío. La Zaranda de Ideas: Revista de Jóvenes Investigadores en Arqueología 4: 109-118.

BAte, L. F. 1998. El proceso de investigación en arqueología. México, D. F.: Crítica.

Berenguer, J. 1985. Evidencias de inhalación de alucinógenos en esculturas Tiwanaku. Chungara 14: 61-69.

Berenguer, J. 1995. Impacto del caravaneo prehispánico tardío en Santa Bárbara, Alto Loa. En Hombre y desierto. Actas del XIII Congreso Nacional de Arqueología Chilena, M. T. Planella, F. Falabella, B. Tagle, V. Manríquez \& M. Planella, eds., vol. I, n. ${ }^{\circ}$ 9, pp. 185-202. Antofagasta: Sociedad Chilena de Arqueología-Universidad de Antofagasta.

Berenguer, J. 1999. El evanescente lenguaje del arte rupestre en los Andes atacameños. En Arte rupestre en los Andes de Capricornio, J. Berenguer \& F. Gallardo, eds., pp. 9-56. Santiago: Museo Chileno de Arte Precolombino.

BERENGUER, J. 2009. Caravaneros y guerreros en el arte rupestre de San Bárbara, Alto Loa. En VII Simposio Internacional de Arte Rupestre, M. Sepúlveda, L. Briones \& J. Chacama, eds., pp. 193-203. Arica: Universidad de Tarapacá.

Bischof, H. 1999. Los mates tallados de Huaca Prieta: ¿evidencias del arte Valdivia en el Arcaico centroandino? Boletín de Arqueología, PUCP 3: 85-119.

Boman, E. 1908. Antiquités de la région andine de la République Argentine et du desert d'Atacama. París: Imprimerie Nationale.

CAmpana, C. 2004. El triángulo escalonado, el poder y la arquitectura en el Antiguo Perú. Arkinka 9 (108): 86-93.

Castro, V. 2001. Atacama en el tiempo. Territorios, identidades, lenguas. (Provincia El Loa, II Región). En Anales de la Universidad de Chile, vi serie, n. ${ }^{\circ} 13$, pp. 1-25. $<$ http://www.revistas.uchile.cl/index.php/ANUC/article/ view/2527/2441> [consultado: 19-08-2019].

Castro, V., J. Berenguer, F. Gallardo, A. Llagostera \& D. Salazar 2016. Vertiente Occidental Circumpuneña. Desde las sociedades posarcaicas hasta las preincaicas (ca. 1500 años AC a 1470 años DC). En Prehistoria en Chile: Desde sus primeros habitantes hasta los Incas, F. Falabella, C. Aldunate, M. Uribe \& L. Sanhueza, eds., pp. 239-279. Santiago de Chile: Universitaria.

Costa, M. A. \& A. Llagostera 1984. Museo Arqueológico R. P. Gustavo Le Paige, San Pedro de Atacama. Serie Patrimonio Cultural Chileno. Santiago: Departamento de Extensión Cultural del Ministerio de Educación.

Dauelsberg, P. 1972. Arqueología del Departamento. En Enciclopedia de Arica, pp. 161-178. Santiago: Editorial de Enciclopedias Regionales Ltda. 
Dauelsberg, P. 1974. Excavaciones arqueológicas en Quiani (Provincia de Tarapacá Dept. Arica). Chungara 4: 7-38.

Durán, E. 1976. Calabazas pirograbadas del Departamento del río Loa y sus correlaciones con áreas vecinas. En Actas y Memorias. IV Congreso Nacional de Arqueología Argentina (Primera Parte), H. Lagiglia, ed. Revista del Museo de Historia Natural San Rafael III (1/4): 119-126. Mendoza: Museo de Historia Natural San Rafael.

Eco, U. 1994. Signo. F. Serra Cantarell, trad. Bogotá: Labor.

Fernández, A. 1980 Ms. El empleo de calabazas por parte de las culturas arqueológicas de los Andes argentino-chilenos. <https://www.academia.edu/33003847/Calabazas_..docx> [consultado: 19-08-2019].

Fuentes, M. \& M. Soto 2009. Un acercamiento a la Arqueología Social Latinoamericana. Cuadernos de Historia Marxista 4: 1-36.

Gallardo, F., G. Cabello \& C. Odone 2011. Arte precolombino chileno. Donación colección Santa Cruz-Yaconi. Santiago: Museo Chileno de Arte Precolombino.

Gentile, M. 2013. El censo de los runa: datos y reflexiones sobre los incas en el Collasuyu. Nueva corónica 2: 91-120.

GreBe, M. E. 1974. Instrumentos musicales precolombinos de Chile. Revista Musical Chilena 28 (128): 5-55.

Grebe, M. E. 1996. Continuidad y cambio en las representaciones icónicas: significados simbólicos en el mundo sur-andino. Revista Chilena de Antropología 13: 137-154.

Hernández, M. I. 1983. Las calabazas prehispánicas de la Puna Centro-Oriental (Jujuy, Argentina). Análisis de sus representaciones. Anales de Arqueología y Etnología 38-40 (primera parte): 77-159.

Horta, H. 2004. Iconografía del Formativo Tardío del norte de Chile. Propuesta de definición e interpretación basada en imágenes textiles y otros medios. Estudios Atacameños 27: 45-76.

Horta, H. 2014. Lo propio y lo ajeno. Definición del estilo San Pedro en la parafernalia alucinógena de los oasis del salar de Atacama. Chungara 46 (4): 559-583.

Horta, H. 2015. El señorío Arica y los reinos altiplánicos (10001450 DC). Complementariedad ecológica y multietnicidad durante los siglos pre-conquista en el norte de Chile. Santiago: Ocho Libros.

Latcham, R. 1938. Arqueología de la región atacameña. Santiago: Prensas de la Universidad de Chile.

Leiva, P. 2015. Calabazas decoradas del Período Intermedio Tardío: aproximación a un análisis iconográfico en el extremo norte de Chile. Tesis para optar al título de Arqueóloga, Facultad de Ciencias Sociales y Jurídicas, Departamento de Antropología, Universidad de Tarapacá.

Le Paige, G. 1977. Recientes descubrimientos arqueológicos en la zona de San Pedro de Atacama. Estudios Atacameños 5: 111-126.

Le Paige, G., B. Bittmann \& L. Núñez 1978. Cultura atacameña. Santiago: Ministerio de Educación, Departamento de Extensión Cultural. <http://www.memoriachilena. cl/602/w3-article-8412.html> [consultado: 19-08-2019].
LizÁrragA, M. 2010. Los queros coloniales y el imaginario clásico y renacentista. Tesis para optar al grado de magíster en Estudios latinoamericanos, Centro de Estudios Culturales Latinoamericanos, Facultad de Filosofía y Humanidades, Universidad de Chile, Santiago.

Louw, E. 1998. Materialist Semiotics. En The Encyclopedia of Semiotics, P. Bouissac, ed., pp. 393-396. Oxford: Oxford University Press.

LuLL, V. 2005. Marx, producción, sociedad y arqueología. Trabajos de Prehistoria 62 (1): 7-26.

Mardones, C. 2012. Kuka, Achuma, Vilca: mito e imagen de plantas sacras andinas. Anales de Historia de la Medicina 22: 13-34.

Martel, A. \& S. Giraudo 2014. Semiótica de la imagen en Arqueología: el caso de los "escutiformes". Revista Chilena de Antropología Visual 24: 21-25.

Mulvany, E. \& V. VAsvari 2009. Experimentación sobre técnicas decorativas en arqueología. En Arqueología argentina en los inicios de un nuevo siglo, vol. II, F. Oliva, N. de Grandis \& J. Rodríguez, comps., pp. 391-404. Rosario: Laborde Libros.

Museo Chileno de Arte Precolombino (mchap) 2012. Chile 15 mil años. Colección Museo Chileno de Arte Precolombino. Santiago: Centro Cultural Palacio La Moneda. $<\mathrm{http}$ //chileprecolombino.cl/exposicion-chile-15-mil-anos/ brindis-por-una-alianza/> [consultado: 22-08-2019].

Museo Chileno de Arte Precolombino (mchap) 2013. Chile antes de Chile / Chile before Chile. Guía de Sala / Exhibition Guide. Santiago: Museo Chileno de Arte Precolombino. <http://www.chileantesdechile.cl/vitrinas/ norte-grande/chicha-ayer-y-hoy/pactos-en-calabazas/> [consultado: 22-08-2019].

Nielsen, A. 1997. El tráfico caravanero visto desde La Jara. Estudios Atacameños 14: 339-371.

NiELSEN, A. 2007. Armas significantes: Tramas culturales, guerra y cambio social en el sur andino prehispánico. Boletín del Museo Chileno de Arte Precolombino 12 (1): 9-41.

Ojeda, O. \& C. Ramírez 1993. Alucinógenos y arte rupestre en el Norte Grande de Chile: un intento explicativo. Revista Historia y Geografía 10: 13-27.

OyArzún, A. 1929. Las calabazas pirograbadas de Calama. Revista Chilena de Historia y Geografía 62 (66): 82-104.

Peirce, C. S. 1974. La ciencia de la semiótica. Buenos Aires: Nueva Visión.

PéreZ, J. A. \& I. Gordillo 1993. Alucinógenos y sociedades indígenas del Noroeste Argentino. Anales de Antropología 30: 299-350.

Plath, O. 1957. El Calabozo, vasija vegetal noble. Mates quemados de Renca. Materas y mates chilenos. En Anuario de la Sociedad Folklórica de México XI, pp. 159-164. <http:// www.oresteplath.cl/obra/colab\%20revistas/calabazo.html> [consultado: 19-08-2019].

Podestá, M., D. Rolandi, M. Santoni, A. Re, M. Falchi, M. Torres \& G. Romero 2013. Poder y prestigio en los 
Andes Centro-Sur. Una visión a través de las pinturas de escutiformes en Guachipas (Noroeste Argentino). Boletín del Museo Chileno de Arte Precolombino 18 (2): 63-88.

Posnansky, A. 1913. El signo escalonado en las ideografías americanas con especial referencia á Tihuanacu. Berlín: Diestrich Reimer.

Preucel, R. 2006. Archaeological Semiotics. Oxford: Blackwell Publish Ltd.

RAVInes, R. 1991. Mates ornamentales del Perú: una tradición prehispánica. Revista del Instituto Andino de Artes Populares del Convenio Andrés Bello 13: 30-33.

RICE, P. 1987. Pottery analysis: a sourcebook. Chicago: The University of Chicago Press.

Rostworowski, M., M. Ramos \& P. Ortiz 2003. Los genitales femeninos en la iconografía andina prehispánica. Revista Psicoanálisis 3: 127-138.

Tantaleán, H. \& M. Aguilar 2013. La arqueología social latinoamericana: de la teoría a la praxis. Bogotá: Universidad de los Andes.
TARragó, M. N. 2000. Chacras y pukara. Desarrollos sociales tardíos. En Nueva historia argentina, M. Tarragó, comp., vol. I, pp. 257-300. Buenos Aires: Sudamericana.

Torres, M. \& D. Repke 2006. Anadenanthera visionary plant of ancient South America. New York: The Haworth Herbal Press.

Troncoso, A. 2011. Personajes fuera de lugar: antropomorfos tardíos en el arte rupestre del norte semiárido de Chile. Intersecciones en Antropología 12: 221-230.

Uhle, M. 1913. Los indios atacameños. Revista Chilena de Historia y Geografía v (9): 105-111. Santiago: La Sociedad.

Uhle, M. 1922. Fundamentos étnicos y arqueología de Arica y Tacna. Quito: Imprenta de la Universidad Central.

Uribe, M. \& L. AdÁn 2004. Acerca del dominio Inka, sin miedo, sin vergüenza. Chungara 36: 467-480.

Volóchinov, V. N. 1976 [1930]. El signo ideológico y la filosofía del lenguaje. R. M. Rússovich, trad. Buenos Aires: Ediciones Nueva Visión. 